\title{
CONSTRUÇÃO DIALÓGICA DO DIREITO: OS DESAFIOS JURÍDICOS DA PÓS-MODERNIDADE À LUZ DE PAULO FREIRE
}

\section{Diego Augusto Diehl}

Acadêmico do $2^{\circ}$ ano noturno da Faculdade de Direito da Universidade Federal do Paraná

RESUMO: Este trabalho tem como objetivo principal trazer reflexões da obra de Paulo Freire para a construção de um novo direito de garantia das demandas populares. Para tanto, serão avaliadas preliminarmente a crise da Modernidade e a decorrente crise do direito de concepção modernista, que preconiza um sujeito universal, individual e autônomo. A partir desta crítica das estruturas jurídicas convencionais e da teoria da ação anti-dialógica desenvolvida por Freire, a dissertação traz aspectos da pós-modernidade e sua transformação, tanto na concepção de sujeito quanto na de linguagem e, considerando-se estas novas relações, reflete sobre a teoria da ação dialógica como forma de libertação em comunhão de toda a sociedade, o que deve se refletir no direito, e até mesmo ser produzido por este, para que ocorra a materialização dos ideais propostos pela república.

PALAVRAS-CHAVE: Direito; Filosofia; Paulo Freire; Pós-modernidade; Paradigma da linguagem. 


\section{INTRODUÇÃO}

Diante da notável crise de paradigmas em que se encontra o Direito na atualidade, urge que analisemos o que levou o ordenamento jurídico de um sistema (considerado) "perfeito", fechado e "promotor de justiça social", a um modelo repleto de contradições e defeitos estruturais, tendo em vista a progressiva discrepância entre direito e as relações sociais.

Este trabalho de forma nenhuma propõe uma solução libertadora, que "resolva" a crise pela qual passa o Direito. Como veremos mais à frente, o direito contemporâneo deve necessariamente estar em crise permanentemente, caso contrário seus paradigmas não se transformariam, e o ordenamento jurídico estaria fadado ao esquecimento, por se tornar tão rígido a ponto de não mais servir à sociedade, que o descartaria como um mero dejeto que mais prejudica que contribui antes de qualquer coisa.

Isto se deve à chamada crise da Modernidade, que transformou profundamente o entendimento humano, com conseqüências sensíveis na relação do sujeito cognitivo com o objeto (tendo em vista as teorizações filosóficas da relação entre sujeito e objeto) e do próprio sujeito consigo mesmo. Esta crise do paradigma da consciência traz reflexos que de forma nenhuma podemos valorar como "bons" ou "ruins". Não se trata de avaliar vantagens ou desvantagens deste novo momento histórico, mas refletir sobre as relações materiais e o papel do Direito a partir da crise dos paradigmas modernos e do advento histórico-filosófico da pósmodernidade, que, por ser um fenômeno recente, nos traz grande insegurança ao propor qualquer tendência, tendo em vista inclusive a forte característica niilista evidenciada por este novo momento.

Existem dúvidas quanto ao caráter pós-moderno da obra de Paulo Freire, as quais serão discorridas ao longo da argumentação. A importância deste pedagogo ao direito é tão importante pelo fato de suas teorizações ambicionarem a mudança de postura do sujeito em relação ao objeto, aos demais sujeitos e a si mesmo, o que exige certamente a ênfase na mudança da linguagem utilizada. Além do mais, são raras as obras jurídicas que tenham em vista a concepção freireana de "re-conhecer" o mundo, a partir de uma ética de tolerância e dialogicidade, grandes características 
deste que é um dos maiores teorizadores e práticos da pedagogia libertária, lembrando que o sujeito necessariamente estabelece uma relação pedagógica com o próprio sujeito a partir do momento em que ocorre a troca de valores morais entre estes, materializada pela linguagem empregada.

\section{CRISE DA MODERNIDADE}

Segundo a concepção de Dussel sobre o projeto da modernidade, trata-se de um momento histórico em que a emancipação racional é colocada em evidência como uma fuga da imaturidade mediante a razão como processo crítico, abrindo à Humanidade um novo desenvolvimento histórico do indivíduo. ${ }^{1}$ É também, e numa perspectiva negativista, a justificação de uma práxis irracional de violência, tendo em vista que a sociedade moderna se vê como "desenvolvida", "superior", que a obrigaria moralmente a "desenvolver" as sociedades mais "primitivas", "bárbaras", por meio de um processo educativo de desenvolvimento semelhante àquele praticado no berço da "modernidade" e, portanto, do "desenvolvimento" (que seria o modelo europeu, "obviamente").

A violência, nesse caso, não seria apenas física, utilizada em "momentos extremos" em que a civilização "bárbara" se recusaria terminantemente a passar pelo processo de "civilização" previsto pelo modelo europeu (a chamada "guerra justa colonial", que visa destruir os obstáculos à modernização), mas também aquela que leva a uma imposição cultural (o conceito de invasão cultural presente na crítica e na obra de Paulo Freire ${ }^{2}$ ), que vai sendo "aceita pacificamente" (neste caso, passivamente) pelo "bárbaro" em franco processo de modernização.

Sem dúvida, essa é uma forma de dominação preconizada pela imposição cultural, que faz do civilizador o dominador, e do bárbaro o dominado, na perspectiva freireana. Essa dominação produz vítimas, encaradas como frutos de um "sacrifício salvador", fazendo não apenas com que a Modernidade se veja como "inocente", mas até mesmo como "emancipadora", teorizada por Freire quando este avalia a práxis do educador anti-dialógico, que se utiliza de elementos falsamente libertadores que, ao final das contas, geram cada vez mais dependência por parte

\footnotetext{
${ }^{1}$ DUSSEL, Enrique. 1942: O encobrimento do outro. Petrópolis: Vozes, 1993.
} 
do dominado, que, em contrapartida, avalia aquele como o "grande salvador" (e, nesse sentido, o paternalismo é um claro exemplo de dominação "pacífica", porque apassivadora).

Esta avaliação "emancipadora" do indivíduo, baseada no racionalismo e na confiança plena na capacidade humana, passa, a partir de meados do século $\mathrm{XX}$, a ser questionada pelo fato de a sociedade moderna garantir direitos formalmente a todos os cidadãos, eliminando todas as suas diferenças e privilégios (que foi a grande conquista preconizada pela Modernidade), e ainda assim as diferenças persistirem materialmente, tendo em vista que o indivíduo - apesar de livre - não consegue usufruir da liberdade garantida legalmente pelo fato de não demonstrar concretamente capacidade para tal (devido à atuação de classes consideradas "mais evoluídas", que prejudicam a auto-afirmação de outras taxadas como "atrasadas"), de forma a emancipar-se e efetivar materialmente as garantias formais que constam do ordenamento jurídico. A partir deste momento, falamos em crise da modernidade como "projeto civilizatório", que tem como norteadores a universalidade, a individualidade e a autonomia.

O universalismo é gravemente afetado pelo particularismo de correntes ideológicas como aquelas marcadas pelo nacionalismo exacerbado, que de tão intransigentes passam a adotar práticas intolerantes (claramente antagônico à ética de tolerância disseminada por Paulo Freire), que se revelam como medidas autoritárias e absolutamente irracionais. Esta, apesar de defenderem valores republicanos em tese, praticam exatamente o contrário, como vimos em governos fascistas ao longo do último século.

Já o individualismo submerge cada vez mais no anonimato do conformismo, tornando o cidadão que participava das ações decisórias de tutela do "bem comum" (característica do republicanismo) em mero consumidor que aliena a si mesmo e é alienado cada vez mais pela sociedade de consumo, demandando maior proteção por parte do Estado, o que leva Zygmunt Bauman a afirmar que a crise da modernidade é a crise da política e da república, de onde constatamos advir a própria crise do Estado e do direito, agravada pela atuação do capital globalizante, que rompe barreiras

\footnotetext{
${ }^{2}$ FREIRE, Paulo. A pedagogia do oprimido. Rio de Janeiro: Paz e Terra, 2003.
} 
políticas e culturais, disseminando a idéia da imprescindibilidade do desmonte do Estado, devido a seus problemas e sua ineficiência. ${ }^{3}$

O último aspecto decisivo da modernidade é a autonomia intelectual, baseada numa visão secular e que vem sendo gradativamente transformada pela volta do reencantamento do mundo. Esta autonomia é ferida, além do mais, pelo próprio processo de barbárie da modernidade, que aliena progressivamente o sujeito inutilizando sua liberdade, tendo em vista a ausência da capacidade de autoafirmação, que leva à autonomia do sujeito.

\subsection{Crise do sujeito}

Dentro do paradigma da modernidade, o sujeito é tratado como fundamento da vida em sociedade, da organização política e do conhecimento. Dentro deste paradigma, o sujeito é universal porque nesta categoria se encaixam todos os seres humanos; individual por ser concreto e independente; e autônomo devido à crença na racionalidade do ser, que teria a condição para prover seu próprio desenvolvimento.

Esse tipo de sujeito possui um caráter abstrato, tendo em vista que todo homem empírico se enquadra na categoria sujeito, o que certamente obrigou o Direito a promover adaptações que se enquadrassem nesta concepção de indivíduo abstrato. Esta abstração ocorre em razão da própria crença na essência do sujeito, que, em tese, seria capaz de garantir sua emancipação a partir da ação racional, levando à supressão das desigualdades preconizadas pelo sistema anterior, que não tratava igualmente os indivíduos, concedendo privilégios às classes "superiores".

Segundo Michel Miaille, ${ }^{4}$ a noção de sujeito de direito é um dado básico do próprio sistema de direito, e tanto isso é verdade que toda a teoria civilista é baseada neste conceito. Segundo a racionalidade do ordenamento, é necessária a existência de direitos que o sujeito seja capaz de exercer, e a Lei vem apenas a complementar a construção da subjetividade moderna, contribuindo para os aspectos definidores do indivíduo como sujeito de direito.

\footnotetext{
3 BAUMAN, Zygmunt. Em busca da política. Rio de Janeiro: Jorge Zahar, 2000.

${ }^{4}$ MIAILLE, Michel. Introdução crítica ao direito. Lisboa: Estampa, 1994.
} 
A partir da perspectiva foucaultiana, não haveria um "ser-em-si" do sujeito, pois este é fruto de uma história recente, resultado de premissas históricas que tornaram possível a sua constituição. Desta forma, estaria descartada a análise do sujeito empírico (pelo fato de poder ser conhecido) para então transcendentalizá-lo (pois teria a capacidade de "re-conhecer" o indivíduo).

A crise do sujeito advém exatamente do fato de ignorar a concepção de sujeito não-transcendental, empírico e histórico, o que representa uma confiança até mesmo ingênua na racionalidade do ser, pois ignorar as diferenças empiricamente existentes permitindo a manutenção do domínio do mais forte de forma nenhuma efetiva materialmente uma igualdade teorizada no período de codificação do direito.

Isto significa dizer que o sujeito empírico não é individual, mas individualizado por práticas normalizadoras que o transformam em força produtiva e docilizada, normalizada e útil à utilização do capitalista, que o utiliza até o momento em que não é mais tão lucrativo quanto um outro indivíduo. Esta prescindibilidade do ser faz com que este esteja constantemente em um estado de provisoriedade, que 0 faz ser um indivíduo de caráter modulado, ou seja, em processo contínuo de mudança, como os próprios móveis modulados. Esta modularização do indivíduo nos remete à crise de um sujeito que passa a rever constantemente seus paradigmas. Sua crise torna-se permanente, e é necessário que assim o seja para que se adapte da melhor forma possível a um objeto que é cada vez mais dinâmico e exigente em termos de flexibilidade.

\subsection{Crise de paradigmas}

A crise do paradigma da consciência, do "Penso, logo existo", que se reflete na crise do sujeito é essencialmente um momento de avaliação crítica do conjunto de valores e crenças atribuídos à Modernidade e que denotam uma determinada forma de solução concreta das situações mundanas, mediante a carga valorativa presente no paradigma predominante, que levava à crença na racionalidade, na consciência do sujeito.

Este momento de avaliação crítica, segundo Thomas Kuhn, é característico da fase da ciência revolucionária, tendo em vista que o paradigma até então aceito pela comunidade científica passa por uma revisão das bases epistêmicas que 
formam o conhecimento científico. Este momento ocorre devido ao acúmulo de problemas que não podem ser explicados pelo paradigma hegemônico, o qual nos remete à exigência de um processo de elaboração de um novo paradigma, e este momento de transição é aquele em que predomina a ciência revolucionária. ${ }^{5}$

Apesar da provisoriedade com que é rotulado este novo momento, certamente o período de construção de um novo paradigma pode denotar muito tempo, podendo inclusive ter caráter ad eternum. Esta conclusão se fortalece quando avaliamos o atual processo de reconstrução paradigmática, que, pelo seu caráter fortemente crítico e nilista, parece mais desconstruir as bases modernas estabelecidas que necessariamente criar novas cargas valorativas.

A crise da modernidade é o momento em que se encerra o otimismo preconizado pelos avanços científicos, os progressos do pensamento humano e a busca de uma sociedade que combinasse a livre iniciativa com a igualdade material dos cidadãos. É uma fase de esgotamento intelectual, desânimo da idéia de que o homem chegaria sozinho à sua emancipação, tendo em vista toda a racionalidade com que este avalia o mundo, além da forma de linguagem utilizada na comunicação dos valores e das vontades.

Porém, este viés niilista não significa necessariamente que não se busca mais a promoção de uma sociedade que objetive a justiça social, mas uma revisão dos meios utilizados para tal. Dessa forma, passamos de um momento de conceitos "definitivos" para uma situação de reconstrução permanente dos paradigmas, e o mais importante neste contexto, segundo Paulo Freire, seria a consciência do sujeito quanto à sua provisoriedade, levando à constante autocrítica em busca do aprimoramento gradativo do ser, afinal de contas, " 0 mundo não é, o mundo está sendo".

A partir desta visão, certamente Paulo Freire deixa de fazer parte do conjunto de pensadores pós-modernos marcados pelo pessimismo em relação ao homem. Ele claramente é otimista, acredita na libertação racional, porém a sutileza da diferença se dá por sua própria teoria da ação dialógica, que tem como destaque a idéia de que "ninguém liberta ninguém, ninguém se liberta sozinho; todos se libertam em comunhão". Esta frase é decisiva na obra de Freire, na medida em que evidencia não uma

\footnotetext{
${ }^{5}$ KUHN, Thomas S. A estrutura das revoluções científicas. 3. ed. São Paulo: Perspectiva, 1992.
} 
confiança cega na racionalidade do sujeito, mas na importância da linguagem utilizada no processo cognitivo entre sujeito e objeto e, principalmente, na relação do sujeito consigo mesmo, em busca de uma práxis verdadeiramente libertária.

Portanto, considerando a concepção pedagógica freireana, a crise da modernidade é a crise da teoria da ação antidialógica, caracterizada pela invasão cultural (no sentido de impor uma cultura "superior"), conquista (a partir da imposição cultural que leva o oprimido a ser "conquistado" pelo opressor, como no caso do paternalismo assistencialista), divisão (que individualiza as demandas dos oprimidos, que não se vêem como condicionados pelo dominador, enfraquecendo-se como classe devido ao isolamento imposto, ainda que de forma não-violenta) e a manipulação (que é decorrente de todos os processos anteriores, que docilizam o dominado, fazendo-o atuar de acordo com os interesses do dominador) ${ }^{6}$.

\subsection{A conseqüente crise do direito}

Os elementos do paradigma da consciência são claramente identificados no ordenamento jurídico atual, até mesmo em uma avaliação mais superficial das leis vigentes. O próprio novo Código Civil, apesar de desenvolvido já neste período de crise paradigmática, reflete concepções universais como a construção do sujeito de direito. O sujeito permaneceu como uma das bases de todo o Código, o que certamente reflete, ainda, a confiança na autonomia do sujeito como garantidor de seus próprios direitos. ${ }^{7}$

Ora, é notória a influência do capital na "mercantilização" do cidadão, e a influência alienante dos poderes hegemônicos (inclusive utilizando-se dos grandes veículos da mídia) é decisiva para um sério ataque à capacidade do indivíduo, que não usufrui da sua liberdade no sentido de se auto-emancipar. A idéia de que "o direito só serve para os ricos", nesse sentido, é materialmente verdadeira, apesar de não haver diferenciação jurídica entre rico e pobre, forte e fraco, tendo em vista que quem tem conhecimento das normas e se utiliza delas para se auto-afirmar é aquele que é "esclarecido" o suficiente para ter a segurança de atuar observando os direitos

\footnotetext{
${ }^{6}$ Termos retirados do último capítulo da "Pedagogia do Oprimido", de Paulo Freire.
} 
garantidos pelo ordenamento (o que é decisivo na concretização do direito, pois grande parte da população muitas vezes tem medo de exigir a prestação jurisdicional, devido ao "pedestal" em que o Direito foi colocado).

Portanto, e se atendo ainda à nova norma infraconstitucional civilista, certamente houve um "progresso" na formalização de direitos já previstos materialmente, além da correção de incoerências e o preenchimento das devidas lacunas (o que de forma nenhuma impede a afirmação de ainda assim ser um sistema lacunoso, o que de certa forma é benéfico para que a jurisdição não perca sua autonomia na concretização da Justiça no caso concreto); porém, o fato de permanecer na crença de que o sujeito tem a capacidade de responder da mesma forma que os demais sujeitos é um grave erro preconizado pelo paradigma da consciência, pois não leva em consideração a opressão imposta pelos detentores dos poderes políticos e econômicos (ainda que não o façam conscientemente). A Lei trata os desiguais igualmente, fomentando a desigualdade material, visto que o forte continua forte, com o agravo de que se fortalece cada vez mais pelo enfraquecimento gradual do fraco, que assim permanece, cada vez menos capaz de promover sua auto-afirmação.

A crise do direito moderno ocorre exatamente devido a esta igualdade formal, que incorre em desigualdade material. Permanecer na posição de defesa do paradigma da consciência parece mais uma tática suicida, pois levaria a tamanho acirramento das relações sociais, além de uma brutal discrepância entre a teorização e a concretização do direito, que nos remeteria à brutalização da sociedade, com a total descrença no Estado como concretizador do ideal republicano e um conseqüente processo de anarquização social, que, neste caso (e sem querer necessariamente dizer que o "assistema" preconizado pela anarquia seria "prejudicial"), teria características de violência e intolerância de classes, e de forma alguma a construção de uma sociedade igualitária se inicia mediante processos caracterizados pela violência ${ }^{8}$.

7 Sobre o tema, ver <http://www.historiadodireito.com.br/textos/sujeito\%20de\%20direito.htm>, que disserta brilhantemente sobre qual o paradigma seguido pelo novo Código Civil Brasileiro, ainda repleto dos vícios do pensamento moderno, evidentemente em crise já há algum tempo.

${ }^{8}$ Recomendamos a leitura do esclarecedor texto sobre o que pretende a ideologia dos anarquistas e como se caracteriza a sua forma de proceder no endereço: <http://www.odialetico.hpg.ig.com.br/ filosofia/anarquia/qpretende.htm>. 
É importante, portanto, discutirmos a construção de um direito livre dos paradigmas modernos, por motivo de sua inviabilidade material, para uma nova concepção de direito, que considere o advento da pós-modernidade não como um momento histórico "bom" ou "ruim", mas como conseqüência do próprio processo histórico da sociedade, de acordo com toda a sua complexidade, e que não pode simplesmente ser negado pelos juristas, sob pena de negarem a própria sociedade.

\section{O PARADIGMA PÓS-MODERNO}

A pós-modernidade é um momento de problematização, desconstrução das categorias da verdade, do tempo e do sujeito até então existentes, e que foram até então atrelados a pressupostos culturais que condicionaram a visão humana. Neste momento ocorre uma nova forma de lidar com o esvaziamento do "eu" (devido ao processo de dessubstancialização do sujeito), a partir da revisão paradigmática do indivíduo.

Porém, e em detrimento da corrente pós-moderna celebratória, este é um momento também de discussão, debate, visando à construção de novos paradigmas, preocupados com a concretização de utopias sociais. É exatamente neste ponto que a diferença é mais sensível entre a pós-modernidade desanimada, estafada pela busca não-concretizada de justiça social, e a corrente crítica, que permanece na busca incansável de novas formas de organização das classes sociais e de participação política preocupadas com a concretização dos direitos inerentes a todos os cidadãos.

É a partir desta idéia, chamada por Rouanet de iluminista ${ }^{9}$ (diferentemente do período da ilustração, denotada pelos pensadores da modernidade), que a pósmodernidade busca uma transformação dos conceitos modernos. Para tanto, o universalismo seria uma forma de assegurar a concretização dos direitos personalíssimos de todos, sem qualquer tipo de distinção e sem acarretar necessariamente a crença na auto-afirmação, que se daria por meio da abstração do sujeito. A individualização passaria então a ter sentido como uma forma de distinção das demandas de sujeitos diferentes, de tratar desigualmente os desiguais, buscando a concretização da sociedade igualitária. Já a autonomia seria 
prerrogativa de todos, devendo ser inclusive tutelada e garantida pelo próprio Estado, que teria a função de evitar que qualquer tipo de força socioeconômica corrompa a concretização da autonomia da vontade.

\subsection{Especialidade da linguagem}

Neste momento de revisão valorativa, surge com força um paradigma que tem em consideração a forma de relação sujeito-objeto e sujeito-sujeito. É o chamado paradigma da linguagem, que passa a levar em consideração não mais a importância do sujeito, mas a importância de como este se comunica com o mundo exterior e consigo mesmo. Ocorre, então, uma fragmentação da filosofia em diversas escolas de entendimento, cabendo exatamente à linguagem o papel de intermediar o conhecimento produzido pelas diversas correntes, e que pode se dar de forma a destruir conceitos preexistentes ou construir novas formas de valoração e percepção sociais.

Isto significa que a razão subjetiva é superada pelo paradigma da razão comunicativa, e a linguagem inicia a reflexão a partir da idéia de intersubjetividade, numa reação dialógica e auto-reflexiva, que respeite a questão da auto-afirmação do sujeito como indivíduo e como classe, o que só será concretizado no momento em que a mentalidade "desenvolvimentista" seja completamente extirpada, em nome de uma construção conjunta que se reflita em benefícios da todos, a partir do que Paulo Freire chama de co-laboração, que é exatamente este processo de laborar em conjunto.

\subsection{A proposta freireana de linguagem}

Em relação à forma de comunicação do ser no mundo, Paulo Freire é categórico quanto à importância de o indivíduo estabelecer uma relação caracterizada pela tolerância, e esta é a principal contribuição do pensamento freireano ao paradigma pós-moderno da linguagem.

Esta tolerância se dá devido à dialogicidade impregnada na ação de libertação, e deve ocorrer no sentido de contribuir no processo de crescimento crítico

\footnotetext{
${ }^{9}$ ROUANET, Sérgio P. Mal-estar na modernidade. 2. edi. São Paulo: Cia das Letras, 1993.
} 
do outro, o que perpassa pelo respeito às opiniões divergentes e à construção política em conjunto, que não seja segregacionista no sentido de isolar qualquer um em função de suas crenças. ${ }^{10}$

Esta afirmação demonstra um caráter eminentemente político da atuação do "ser no mundo", sendo algo realmente da sua essência, na medida em que é um sujeito em constante contato com a sociedade, que, a partir da linguagem, materializa suas crenças, seus ideais, que objetivam causar convencimento aos demais sujeitos.

Àqueles que trabalham para mobilizar as classes populares, demonstrando todo o caráter exploratório do sistema capitalista e buscando convencer da importância da atuação política de cada um para fazer valer os interesses populares, é ainda mais importante ter em vista a necessidade de não promover a imposição ideológica, o que levaria a uma atuação política viciada, de indivíduos absolutamente sem conviç̧ão da real necessidade de mobilização, o que certamente levaria tal movimento a um fracasso tão significativo que possivelmente levaria a um aprofundamento da auto-alienação políticas das classes populares.

Atuar politicamente sem convicções ideológicas é absolutamente impossível, pois todo conhecimento é reflexo de uma dada postura ideológica. A importância está na forma de comunicação dessa ideologia, que deve ser caracterizada pela síntese cultural, ou seja, pela construção dialógica de um entendimento que reflita realmente o pensamento das partes, o que de forma nenhuma gera "consenso" (e nem haveria de gerar) pelo fato de não representar "con-vencimento", mas "colaboração", construindo propostas plurais, que respeitem a opinião de todos, sem a valoração de "pior" e "melhor", mas como uma forma de "re-conhecer" o mundo, que não deve ser igual a todos. ${ }^{11}$

\subsection{A construção da sociedade dialógica}

Uma sociedade dialógica certamente é caracterizada pelo respeito ideológico representado por cada sujeito, juntamente com a construção política, que perpassa pela discussão aprofundada dos problemas existentes. Esta

\footnotetext{
${ }^{10}$ FREIRE, Paulo. Educação como prática da liberdade. Rio de Janeiro: Paz e Terra, 1999.
} 
discussão necessariamente (e se efetuada de forma respeitosa, tolerante, atendose às idéias) levará à constituição de idéias mais claras que refletem em uma prática mais consciente.

Isto significa que problemas como o vandalismo ao patrimônio público, por exemplo, não levariam a um castigo que não educa de forma alguma, e que apenas impõe o medo em ser novamente punido (e com maior rigor, devido à reincidência), mas por uma real conscientização quanto à necessidade de preservar bens públicos que são úteis a todos, o que leva a uma atuação que, além de respeitar os direitos humanos, reproduz uma lógica de união e colaboração para corroborar com o bem estar de todos.

A prática dialógica não reconhece valorativamente (no sentido de "bom" ou "mau") as atitudes, pois elas diferem-se radicalmente de um sujeito para outro. Ela pondera a individualidade do "ser no mundo" e todo o processo que o levou a agir (ou a não agir, o que também representa uma ação no sentido de optar pela inércia). Certamente é uma lógica muito mais complexa, pois não é simplista ao ponto de enumerar quais os motivos que levam alguém a ferir o direito de outrem, mas objetiva um entendimento que leve em conta toda a complexidade que motiva uma simples ação que tenha relevância socialmente.

A construção, que, como vimos, é determinada pela "co-laboração", demonstra linguagem também diferenciada no sentido de não mais promover a dominação do sujeito, mas a união, que leva todos a se reconhecerem como seres sociais que respeitam e são respeitados. Este tipo de organização perpassa por uma postura necessariamente participativa da sociedade, que exige a revisão do atual modelo representativo posto.

O modelo político representativo, idealizado como um modelo que racionalizava o Estado, que ganhava maior rapidez de decisão e atuação levou à alienação política dos representados, pelo fato de já haver representantes com a função de promover o bem público. Materialmente, isto gerou a falsa consciência de que são os representantes os responsáveis únicos dos graves problemas sociais

\footnotetext{
${ }^{11}$ Idem. A pedagogia do oprimido.
} 
pelos quais passamos, como se não coubesse a cada cidadão proteger o bem público (e não necessariamente os bens materiais), como seres sociais que são. ${ }^{12}$

O auto-reconhecimento do ser também como também responsável pela tutela do interesse público apenas pode ser resgatado por processos de radicalização democrática, que perpassam pela atuação do Estado, que seja motivada diretamente pelos interesses populares, o que exigiria a mobilização e conscientização da importância de cada um neste processo de organização, união, colaboração e síntese cultural. A partir do momento em que o modelo político é caracterizado pela participação direta da população, certamente os reflexos no modelo de Direito são brutais.

\section{$3 \quad$ REFLEXOS PÓS-MODERNOS NO DIREITO}

O momento pós-moderno é aquele em que se torna clarividente não apenas a parcialidade da Lei (por carregar normas de cunho ideológico para garantir determinados bens, e até mesmo o status quo), e a crise do Direito torna-se evidente na medida em que não mais responde às demandas sociais que se intensificam a cada momento.

Os reflexos desta crise pela qual passa todo o ordenamento jurídico e suas instituições coercitivas determinam uma crescente descrença no poder do Direito em garantir a manutenção de uma sociedade justa e igualitária, tendo em vista que materialmente a sociedade não o é desta forma, e portanto não haveria sentido em procurar manter as relações estabelecidas entre sujeitos, bem como sua relação com o objeto jurídico, que seria pretensamente a garantia de uma convivência harmoniosa.

A partir deste momento, fala-se em "uso alternativo do Direito", em métodos não-jurídicos para a resolução de conflitos e, ainda, na construção de novos paradigmas jurídicos que tenham em vista a incapacidade material de determinadas classes em promover sua auto-afirmação. Wolkmer cita, por exemplo, o estabelecimento de um novo tipo de sujeito de direito, o sujeito coletivo, que seria

\footnotetext{
${ }^{12}$ WOLKMER, Antônio C. Pluralismo jurídico: fundamentos de uma nova cultura no direito. São Paulo: Alfa Omega, 1994.
} 
tratado de forma "especial" por representar demandas de alta relevância social, o que materialmente significa tratar os desiguais de forma também desigual. ${ }^{13}$

A própria prestação jurisdicional, de certa forma possui este cunho "livre" para arbitrar sobre a relevância social da demanda das partes, e, a partir de então, definir que natureza de decisão seria justa para garantir a concretização dos direitos fundamentais, consoante com a garantia da manutenção da "segurança jurídica". ${ }^{14}$

Esta segurança parece ser cada vez mais posta em cheque a partir do uso alternativo do Direito, pois subverte valores previstos na Lei (que quase integralmente refletem ideologias de conservação do status quo) para uma melhor conformação do Direito às relações sociais. Esta situação parece nos levar a um momento decisivo em que devemos optar ou pela utilização alternativa do ordenamento (negando a própria segurança jurídica pretendida pelas codificações) ou pela elaboração de novos ordenamentos (que refletiriam as relações materiais, mas teriam de ser revistos constantemente, devido à dinâmica social), sem que o juiz perdesse sua autonomia decisória, tendo em vista as particularidades do caso concreto.

Este novo momento se reflete, ainda, na transformação das formas empregadas para construir, concretizar e garantir o Direito, de forma a estabelecer relações sociais que sejam materialmente (e não apenas formalmente) preocupadas com a igualdade e a justiça sociais.

\subsection{A transformação de sujeito e objeto}

Com relação ao sujeito, com já citado anteriormente, autores da corrente do chamado "Direito Alternativo" defendem uma revisão na avaliação jurídica do conceito de sujeito, para que não se permita materialmente a um sujeito se sobrepor a outro devido à uma influência (política, econômica, social etc.) praticada de modo a cercear a auto-afirmação dos demais.

\footnotetext{
13 Idem. Ibidem.

14 Sobre este tipo de prestação jurisdicional, ver o artigo do professor da Luiz Guilherme B. Marinoni em <http://www.professormarinoni.com.br/admin/users/27.pdf>.
} 
Isto significa tratar os desiguais de forma desigual, de forma a levar em conta toda a complexidade de uma relação social condensada em um processo judicial, de forma a tutelar os direitos fundamentais de todos os cidadãos, e de forma a tentar evitar que o conflito permaneça ainda que terminado o litígio.

Portanto, além de ser indispensável a prática alternativa do juiz em relação ao conflito, é imprescindível que haja o debate sobre a mudança na concepção jurídica de sujeito, que tenha em vista toda a complexidade social, e talvez criando novas espécies de sujeitos (os sujeitos coletivos, citados por Wolkmer) que auxiliem nesta concretização material da justiça.

Apesar disso, há que se ponderar se a crença em um ordenamento que, grosso modo, defende interesses dominantes seria o modo correto de atuação de um jurista que busque a construção de um Direito realmente justo. Apesar das críticas a este viés niilista de avaliação da construção do Direito, certamente há que ser considerado o fato de que o processo de construção das Leis em si ocorra mediante instituições que apenas reproduzem a lógica dominante. Talvez seja hora de levar este debate à população em geral, para que esta tome realmente conhecimento de todos os vícios de um ordenamento que a maioria confessa desconhecer totalmente (o que se torna uma poderosa arma às classes dominantes, que se preocupam em conhecer o Direito, e encontrar vias legais, porém antiéticas, para agirem sem serem punidas).

\subsection{Reflexos do paradigma da linguagem}

A partir deste novo momento, em que o Direito é visto de forma menos "legalista" e mais preocupado com a concretização material dos direitos fundamentais, é necessário avaliar qual seria o papel da linguagem frente a sujeito e objeto diferentes, transformados em modelos que poderiam ser meramente ilustrativos, no sentido de delimitar a relação de um com outro.

Há que se resgatar o papel pedagógico-político, citado anteriormente, para avaliar a importância da atuação do jurista socialmente responsável. Isto significa que é necessário rever o papel de imposição evidenciado pelo juiz atualmente, que a partir do processo de conhecimento do litígio (e com todos os vícios deste) profere uma decisão que obriga, pune, e não se preocupa necessariamente (e há de se 
convir que há exceções a esta regra) com o caráter pedagógico de uma sentença, que deve ser muito mais preocupada com o papel de conscientização quanto à importância de respeitar determinados direitos (e aí seriam os direitos reconhecidos eticamente, mesmo que não tipificados em Lei), de forma a garantir a harmonização social (que busca o pacifismo, e não a passividade, o que é uma diferença tão sutil quanto importante em todo este processo).

\subsection{A construção dialógica do direito}

A partir do momento em que se cogita a construção de um novo modelo político preocupado com a participação popular e a quebra da apatia reinante até então, certamente é necessário que haja debate também sobre a abertura radical do processo de construção do direito. Esta abertura se daria no sentido de construir novos modelos que fomentem a participação popular, de forma a garantir que 0 direito seja realmente reflexo dos interesses da população em geral, o que não ocorre hoje, tendo em vista nosso bizarro modelo político representativo, que elege supostos representantes do povo, que, comprovadamente, não defendem interesses populares (no máximo interesses populistas, obviamente se excluindo as exceções de políticos idôneos).

Afirmar que o povo não possui cultura jurídica para tal é apenas mais um discurso para retirar do povo o direito de elaborar o código de conduta social ao qual todos devem ser vinculados. Como vemos em diversas situações, os códigos de conduta paralelos aos do Estado (criados pelo povo, e geralmente por pessoas sem nenhum conhecimento jurídico formal) são muito mais justos que aquele determinado pelo poder público.

Portanto, há que se reconhecer a necessidade em trazer a população à discussão de um modelo jurídico verdadeiramente popular, sob pena de o Estado perder cada vez mais seu aspecto de protetor dos interesses sociais, que levaria à fragmentação da sociedade em diversos grupos com códigos de ética alternativos, que não mais se vinculariam ao Estado, por não mais o considerar legítimo no sentido de representar a vontade popular. Salientando sempre que esta discussão, voltada à "co-laboração", deve ser caracterizada pela síntese cultural, e nunca por uma práxis antidialógica de conquista e manipulação. 


\subsection{O conceito de jurisdição consensual}

É difícil vislumbrar o advento de uma forma de jurisdição que promova o consenso entre as partes constantes no processo, pelo fato de o litígio lidar com demandas geralmente conflitantes, que dificilmente poderão ser apaziguadas pelo juiz.

A prática da chamada jurisdição consensual, porém, pode ser muito melhor visualizada nos juizados especiais, por exemplo, para que a decisão jurisdicional garanta o convívio pacífico entre os cidadãos. Para tal, primeiramente a postura do próprio magistrado deve ser de dialogicidade, de procurar ouvir e entender as demandas daqueles que exigem a prestação jurisdicional. Principalmente para a população mais carente de proteção do Estado, e que geralmente é apenas criminalizada por este, a palavra, a postura do juiz obtém respaldo, respeito, o que é deveras importante para a prática da tolerância e do pacifismo, pois o indivíduo passa a ponderar as observações do juiz, que, caso proferidas responsavelmente, geralmente levam a uma revisão de postura das partes em relação ao litígio.

A jurisdição consensual, portanto, é uma forma de atuação do juiz que busca preponderantemente o diálogo entre as partes, objetivando não apenas a resolução daquele conflito pontual, mas também dos futuros conflitos, para que sejam tratados a partir da práxis da tolerância entre os próprios conflituosos. Esta é uma medida muito importante, tendo em vista que a partir do momento em que uma pequena desavença é remetida para a prestação jurisdicional, ainda que no setor de pequenas causas, ocorrerá necessariamente a criminalização daquela situação, e qualquer novo conflito que envolva qualquer das partes poderá acarretar o agravamento, seja da atuação policial, seja da prestação jurisdicional, exatamente pelo fato de já haver um histórico de problemas.

Portanto, mais que uma autoridade, o juiz deve ser um orientador; mais que um jurista, deve ser um verdadeiro psicólogo, e sua jurisdição deve ser, acima de tudo, de caráter pedagógico, no sentido de promover um entendimento entre as partes de que, em muitas situações, o espaço de resolução de conflitos não é necessariamente o Fórum judicial, e nem a polícia é treinada para tal (infelizmente, diga-se de passagem). Esta é uma medida importante, pois, de certa forma, desacredita da Justiça o caráter de pacificação, até porque a partir do momento em 
que o réu é condenado por um pequeno delito em tese cometido, esta condenação é remetida ao histórico do condenado e se refletirá mais tarde em agravantes, caso volte a praticar delitos, por menor potencial ofensivo que ofereça, o que certamente está longe de uma práxis de pacificação social.

\section{CONCLUSÃo}

Como visto, a descrença neste Direito "moderno", que crê na concretização da igualdade material, leva-nos a desconstruir o que está posto e, quando muito, sugerir novas formas (em diversos casos não muito claras) de produção jurídica preocupada com a materialização da justiça. Talvez até mesmo esta descrença nos "órgãos oficiais" seja característica de um Estado em processo de "desmodernização", que desacredita do direito o fato de ser a única fonte oficial de resolução de conflitos.

Isto nos leva a citar aqueles que teorizaram sobre um novo tipo de Direito, de política e de sociedade, que sejam caracterizados não mais pela valoração dos seres, mas pelo respeito às suas idéias, à tolerância na linguagem utilizada, e na busca de uma construção política, jurídica e, principalmente, social voltadas ao reconhecimento do sujeito como ser de direitos, limitado por todos os seus vícios e pela sua relação com o mundo exterior a si mesmo.

Este momento de reconhecimento da complexidade das relações sociais leva-nos a abandonar definitivamente o simplismo caracterizado por um projeto de Justiça que se preocupe apenas em "concretizar a vontade da Lei", garantindo a segurança jurídica em detrimento da promoção material da justiça.

A partir deste momento histórico, há que se reconhecer o caráter atrasado do Direito posto e buscar novas formas de constituição do direito e do Estado, a partir de técnicas que visem à libertação do homem a partir das suas relações pedagógicas (e também políticas) com os demais homens. É a partir destas premissas que poderemos, só então, promover uma discussão que seja plural (e pluralizante), democrática e socialmente responsável, e por isso, cremos que o jurista realmente preocupado com estas questões deve conhecer a obra de Paulo Freire, que certamente é aquele que melhor teorizou sobre esta nova forma de tratar o sujeito como "ser no mundo", a partir da dialogicidade e da tolerância constantes. 


\section{BIBLIOGRAFIA}

BAUMAN, Zygmunt. Em busca da política. Rio de Janeiro: Jorge Zahar, 2000.

DUSSEL, Enrique. 1942: O encobrimento do outro. Petrópolis: Vozes, 1993.

FREIRE, Paulo. A pedagogia do oprimido. Rio de Janeiro: Paz e Terra, 2003.

FREIRE, Paulo. Educação como prática da liberdade. Rio de Janeiro: Paz e Terra, 1999.

KUHN, Thomas S. A estrutura das revoluções científicas. 3. ed. São Paulo: Perspectiva, 1992.

MARINONI, Luiz G. B. A jurisdição no Estado Constitucional. <http://www.professormarinoni.com.br/ admin/users/27.pdf>, acessado em 01/07/2005.

MIAILLE, Michel. Introdução crítica ao direito. Lisboa: Estampa, 1994.

MONTOYA e GUANDALINI JR. O sujeito de direito e o novo código civil - desonra ou harpias? <http://www.historiadodireito.com.br/textos/sujeito\%20de\%20direito.htm> , acessado em 01/07/2005.

ROUANET, Sérgio P. Mal-estar na modernidade. 2. ed. São Paulo: Cia das Letras, 1993.

WOLKMER, Antônio C. Pluralismo jurídico: fundamentos de uma nova cultura no direito. São Paulo: Alfa Omega, 1994. 